\title{
The study of image schemas in Hafez Poems: Cognitive perspective
}

\author{
Tayebeh Asgari \\ Linguistic Department, Islamic Azad University - Research and science branch, Tehran- Iran
}

Email address:

Asgari.Tayebeh@yahoo.com

\section{To cite this article:}

Tayebeh Asgari. The Study of Image Schemas in Hafez Poems: Cognitive Perspective. International Journal of Language and Linguistics. Vol. 1, No. 4, 2013, pp. 182-190. doi: 10.11648/j.ijll.20130104.23

\begin{abstract}
This article analyzes image schemas in Hafez sonnets. After studying the sonnets, some verses chosen selectively then, analyzed descriptively and analytically, based on some image schemas mentioned by Johnson ( 1987). Image schemas are conceptual structures derived from physical experiences, cultural background and ideology of a nation. All human beings based on their unique characteristics have access to a universal collection of image schemas, such as containment, path and force schemas. But, culturally image schemas are represented differently in languages. This fact considered by Lakoff in forming conceptual metaphors and cultural differences in Metaphors We Live By. Obviously, poem is rhymed words and suitable to image conceptual structures such as metaphors and image schemas. It is essential to mention that conceptual structures mentioned are not just used in poetry but, in everyday language as well. Here, some sonnets by Hafez are analyzed as the corpus of this article.
\end{abstract}

Keyword: Image Schemas, Cognitive Linguistics, Cognitive Semantics, Metaphors

\section{Cognitive Linguistics}

Cognitive linguistics came from interest that researchers held in the connection between language and the mind in $1970 \mathrm{~s}$. It is characterized by adherence to three central positions. First, it denies that there is an autonomous linguistic faculty in the mind; second, it understands grammar in terms of conceptualization; and third, it claims that knowledge of language arises out of language use. Cognitive linguists deny that mind has any module for language acquisition that is unique and autonomous. This stands in contrast to the stance adopted in the field of generative grammar. They also argue that knowledge of linguistic phenomena i.e., phonemes, morphemes, and syntax - is essentially conceptual in nature. However, they assert that the storage and retrieval of linguistic data is not significantly different from the storage and retrieval of other knowledge, and that use of language in understanding employs similar cognitive abilities to those used in other non-linguistic tasks. ( Croft and Cruse, 2004)

The stage was set for cognitive linguistics in the nineteen seventies and early eighties with Len Talmy ś work on figure and ground (2000), Ronald Langackerś cognitive grammar framework (1987/1991), George Lakoff ś research on metaphor, gestalts, categories and prototypes (1980 ), Fillmore ś frame work semantics (1982), and Fauconnier ś mental spaces (1994).

Noam Chomsky put forth the theory that language is innate. Cognitive linguists rejected this notion and saw language acquisition as a learning process not different from the process of learning other skills.

One of the most important principles of cognitive linguistics is that meaning is central to language to the extent that it should be the primary focus. The structures of language are strongly connected to the semantics, they seek to depict. Linguistic specialists seek to understand how semantics and syntax work together, to understand the relationship between language and thinking. They also try to understand how language influences, how people form concepts.( Kemmer,2007)

Cognitive linguists seek to understand how memory, categorization, imagery and attention affect language. They try to create psychological models for language that cover various linguistic phenomena, such as figurative language. This area of study covers multiple disciplines, such as brain, imaging and language acquisition. Cognitive linguists rely on empirical observation, neuroscience and experimental 
psychology. They see grammar as coming from the properties of neural systems. They also study and theorize about the functional principles of linguistic organization.

\section{Cognitive Semantics}

Cognitive semantics is part of the cognitive linguistics movement. The main tenets of cognitive semantics are first; the grammar is conceptualization, second, that conceptual structure is embodied and motivated by usage, and third, that ability to use language draws up on general cognitive resources and not a special language module. (Croft and Cruse, 2004)

Classic theories in semantics (in the tradition of Alfred Tarski and Donald Davidson) have tended to explain the meaning of parts in terms of necessary and sufficient conditions, sentences in terms of truth- conditions, and composition in terms of propositional functions. Each of these positions is tightly related to the others. According to these traditional theories, the meaning of a particular sentence maybe understood as the conditions under which the proposition conveyed by the sentence hold true. For instance, the expression "snow is white" is true if and only if snow is, in fact, white. Lexical units can be understood as holding meaning either by virtue of set of things they may apply to ( called the " extension" of the world), or in terms of the common properties that hold between these things ( called it's " intension"). The intension provides an interlocutor with the necessary and sufficient conditions that let a thing qualify as a member of some lexical unit's extension. Roughly, propositional functions are those abstract instructions which guide the interpreter in taking the free variables in an open sentence and filling them in, resulting in a correct understanding of the sentence as a whole, (Croft and Cruse, 2004).

Meanwhile, cognitive semantic theories are typically built on the argument that lexical meaning is conceptual. That is, meaning is not necessarily reference to the entity or relation in some real or possible world. Instead, meaning corresponds with a concept held in the mind based on personal understanding.

\section{Metaphor in Cognitive Semantics}

Metaphor commonly means saying one thing while intending another, making implicit comparisons between things linked by a common feature, perhaps even violating semantic rules.

Metaphor is for most people a device of the poetic imagination and the rhetorical flourish - a matter of extraordinary rather than ordinary language. Moreover, metaphor is typically viewed as characteristic of language alone, a matter of words rather than thought or action. For this reason, most people think they can get along perfectly well without metaphor. Johnson and Lakoff have found, on the contrary, that metaphor is pervasive in everyday life, not just in language but in thought and action. Our ordinary conceptual system, in terms of which we both think and act, is fundamentally metaphorical in nature. The concepts that govern our thought are not just matters of the intellect. They also govern our every day functioning down to the most mundane details. Primarily on the basis of linguistic evidence, they have also mentioned that most of our ordinary conceptual system is metaphorical in nature. (Lakoff and Johnson, 1980, 2003).

The most important claim that Johnson and Lakoff have made in Metaphor We Live By is that, metaphor is not just a matter of language, that is, of mere words. They argue that, on the contrary, human thought processes are largely metaphorical. This is what they mean when they say that the human conceptual system is metaphorically structured and defined. Metaphors as linguistic expressions are possible precisely because there are metaphors in a person ś conceptual system (Johnson and Lakoff, 1890,2003).

\section{Conceptual Metaphor}

Some theories have suggested that metaphors are not merely stylistic, but that they are cognitively important as well. Conceptual metaphors are seen in language in our every day lives. They shape not just our communication, but also the way we think and act. In Gorge Lakoff and Mark Johnson's work, Metaphors We Live By (1980), we see how everyday language is filled with metaphors we may not always notice. Conceptual metaphors are used very often to understand theories and models. A conceptual metaphor uses one idea and links it to another to better understand something. Basic conceptual metaphors are part of the common conceptual apparatus shared by members of a culture. They are systematic in that there is a fixed correspondence between the structures of the domain in terms of which we are understanding it (e.g, departure). We usually understand them in terms of common experiences. They are largely unconscious, though attention maybe drawn to them. Their operation in cognition is almost automatic. And they are widely conventionalized in language, that is, they are a great number of words and idiomatic expressions in our language whose meanings depend on those conceptual metaphors.(Lakoff and Johnson, 1890)

\section{Image Schemas}

An image schema is a recurring structure within our cognitive processes which establishes patterns of understanding and reasoning. They are directly meaningful ( $\square$ experiential $\square / \square$ embodied $\square$ ), preconceptual structures, which arise from or are grounded in, human recurrent bodily movements through space, perceptual interactions, and ways of manipulating objects.

- Image schemas are highly schematic gestalts which capture the structural contours of sensory- motor experience, integration information from multiple modalities. 
-Image schemas exist as continuous and analogue patterns beneath conscious awareness, prior to and independently of other concepts. Johnson believes that an image schema is a recurring dynamic pattern of our perceptual interactions and motor programs that gives coherence and structure to our experience.... Experience .... is to be understood in a very rich, broad sense as including basic perceptual, motor- program, emotional, historical, social and linguistic dimensions.( Johnson,1987)

The term is explained in Mark Johnson's book The Body in the Mind (1987), in case study of Gorge Lakoff's women, Fire and Dangerous things ( 1987) and by Rudolf Amheim in visual thinking.

As gestalt, image schemas are both internally structured, i.e., made up of very few related parts, and highly flexible. This flexibility becomes manifest in the numerous transformations they undergo in various experiential contexts, all of which are closely related to perceptual (gestalt) principles. The initial identification of image schemas was mainly achieved through the cross- linguistic analysis of concepts of motion and spatial relations the informal analysis of the phenomenological contours of everyday experience.( Hampe,2005)

In contemporary cognitive linguistics, an image schema is considered an embodied paralinguistic structure of experience that motivates conceptual metaphor mappings . Evidence for image schemas is drawn from a number of related disciplines, including work on cross - modal cognition in psychology, from spatial cognition in both linguistics and psychology, and from neuroscience.

Image schemas are dynamic embodied patterns - they take place in and through time. Moreover, they are multi modal patterns of experience, not simply visual. For instance, consider how dynamic nature of the containment schema is reflected in the various spatial senses of the English world out. Out may be used in case where a clearly defined trajactor (TR) leaves a spatially bounded landmark (LM), as in

(1a) John went out of room.

(1b) Mary got out of car.

(1c) Spot Jumped out of pen.

In the most prototypical of such cases the landmark is a clearly defined container. However, out may also be used to indicate those cases where the trajectory is a mass that spreads out, effectively expanding the area of the containing land mark:

(2a) She poured out the beans.

(2b) Roll out the carpet.

(2c) Send out the troops.

Finally, out is also often used to describe motion along a linear path where the containing landmark is implied and not defined at all:
(3) The train started out for Chicago.

Experientially basic and primarily spatial image schemas such as the containment schema and its derivatives the out schema as lend their logic to non - spatial situations. For example, one may metaphorically use the term out to describe non - spatial experiences.

4) Leave out that big log when you stack the firewood. (Schema used directly and non - metaphorically.)

4 a) I don't want to leave any relevant data out of my argument. (Schema metaphorically projected on to argumentation.)

4 b) Tell me your story again, and don't leave out any details. (Schema metaphorically projected on to story telling.)

4 c) she finally came out of her depression. (schema metaphorically projected onto emotional life). (Johnson, 1987)

Johnson argues that more abstract reasoning is shaped by such underlying spatial patterns - for example, he notes that the logic of containment is not just a matter of being in or out of the container. For example, if someone is in a deep depression, we know it is likely to be a long time before they are well. The deeper the trajector is in the container, the longer it will take for the trajector to get out of it. Similarly, Johnson argues that transitivity and the law of the excluded middle in logic are underlaid by preconception embodied experiences of the containment schema.

\section{Properties of Image Schemas}

Image schemas are preconception in origin. However once the recurrent patterns of sensory information have been extracted and stored as an image schema, sensory experience gives rise to a conceptual representation. This means that image schemas are concepts, but of a special kind: they are the foundations of the conceptual system, because they are the first concepts to emerge in the human mind, and precisely because they relate to sensory perception experience, they are particularly schematic. Sometimes it is more difficult to grasp the idea of an image schematic concept than it is to grasp the idea of a very specific concept like CAT or BOOK. This is because these specific concepts relate to ideas that we are aware of 'knowing about'. In contrast, image schemas are so fundamental to our way of thinking that we are not consciously aware of them: we take our awareness of what it means to be a physical being in a physical world very much for granted because we acquire this knowledge so early in life, certainly before the emergence of language. (Tompskin and Lawley,2000) 
Lists of image schemas

Johnson provided an initial list of image schemas in the Body in the Mind ( P. 126), we mention them then, go into their definitions.

Spatial motion group
Containment
Path
Source- path- goal
Blockage
Center - periphery
Cycle
Cyclic climax
Force Group
Compulsion
Counterforce
Diversion
Removal of restraint
Enablement
Attraction
Link
Scale
Balance group
Axis balance
Point balance
Twin - pan balance
Equilibrium

Now we go into the definition of mentioned image schemas.

-Containment schema

A containment schema is an image schema that involves a physical or metaphorical

-boundary,

-enclosed area or volume, or

- excluded area or volume. (Johnson,1987)

-Example:

-John has gone into a deep depression after divorc.

-Path schema

A path schema is an image schema that

-involves physical or metaphorical movement from place

to place, and

-consists of a starting point, a goal, and a series of intermediate points.

Examples:

Physical

-paths

-trajectories

Metaphorical

The purpose- as-physical-goal metaphor, like the following sentence:

Tom has gone a long way toward changing his personality.(Johnson,1987)
-Force schema

A force schema is an image schema that involves physical or metaphorical causal interaction. It includes the following elements:

-A source and target of the source

-A direction and intensity of the source

-A path of motion of the source and /or target

-A sequence of causation

- Examples:

-physical

-wind

- gravity

-Metaphorical

-Love -as-a-physical-force

-Justice - as-balance (Johnson, 1987 )

- Attraction schema

An attraction schema is a force schema in which an object exerts a force on another object, either physically or metaphorically, to pull it toward itself.

-Examples:

-Physical

-Magnetism

-Vacuum cleaner

-Gravity

-Metaphorical

-Romance

-Desire (Johnson, 1987)

-Removal of restraint

A restraint removal schema is a force schema that involves the physical or metaphorical

-removal of a barrier to the action of a force, or

-absence of a barrier that was potentially present.

Example:

-John did his best and passed the exam. (Johnson,1987)

-Balance schema

A balance schema is a force schema that

-provides an understanding of physical or metaphorical counteracting forces

-is based on a prototypical schema consisting of countervailing forces acting on a target that is

-point

-liner, or

-plane

-is based on bodily experience, such as maintaining

-erect posture

-normal bodily states, such as temperature, and

-may be applied metaphorically to provide an understanding of other experiences, such as balance of the visual field with respect to art.(Johnson, 1987 )

Here are some kinds of balance schemata:

-Equilibrium schema

A equilibrium schema is a balance schema that involves 
physical or metaphorical external and internal pressure on container- like objects.

Examples:

-pressure in the stomach

-Some aspect of psychological balance, such as when emotions are said to be capable of $\square$ exploding $\square$ and thus in need of being

-repressed

-suppressed, and

-hold in.

-He had to suppress his anger. (Johnson,1987)

-Twin- pan balance schema

A twin -pan balance schema is a balance schema that involves physical or metaphorical countervailing forces acting on either side of a fulcrum.

Examples:

-scales

-see-saws

Metaphorical

-Argument- as- balance

-Justice- as -balance

-Mathematical -equality- as - balance.(Johnson1,1987)

-Blockage schema

A blockage schema is a force schema in which a force is physically or metaphorically stopped or redirected by an obstacle.

Example:

A crawling baby encountering a wall is stopped or redirected by the wall.( Johnson,1980)

-Compulsion schema

A compulsion schema is a force schema that involves an external force physically or metaphorically pushing ,or tending to push, an object.

Example:

The experiences of being pushed by

-wind

-water, or

-a moving crowd.(Johnson, 1987

-Counter force schema

A counter force schema is a force schema that involves the active meeting of physically or metaphorically opposing forces.

Examples:

-The experiences of

-football players, and

-participants in head-on auto collisions. (Johnson, 1987)

-Diversion image schema

A diversion image schema is a force schema that involves forces that physically or metaphorically meet and produce a change of direction.

Example:

- Being pushed off course by wind or current while rowing. (Johnson 1897)

-Enablement schema

An enablement image schema is a force schema that involves having

-the physical or metaphorical power to perform some act, or

- a potential force and the absence of blockage counterforce.( Johnson, 1987)

Example:

He finally could lift that big rock and people who were stuck in the cave were survived.

-Link schema

A link schema is an image schema that consists of two or more entities, connected physically or metaphorically, and the bond between them.

-A child holding her motherś hand. (Johnson, 1987)

-Center-periphery schema

A center -periphery schema is an image schema involving

-A physical or metaphorical core and edge, and

-degrees of distance from the core.

-Example:

- The structure of an apple (Johnson,1987)

-Cycle schema

A cycle schema is an image schema which involves repetitious events and event series. Its structure includes the following:

-A starting point

-A progression through successive events without backtracking

-A return to the initial state

The schema often has superimposed on it. A structure that builds toward a climax and then goes through a release or decline.

Example:

-Days, weeks,years (Johnson, 1987)

-Part- whole schema

A part-whole schema is an image schema involving physical or metaphorical wholes along with their parts and configuration of the parts.

Examples:

Physical

- The body and its parts

Metaphorical

-The family (Lakoff, 1987)

-Scale schema

Scale schema is an image schema that

-involves an increase or decrease of physical or metaphorical amount, and

-consists of any of the following:

-A closed- or open- ended progression of amount 
-A position in the progression of amount

-One or more norms of amount

-A calibration of amount

Example:

- Economic entities such as supply and demand ( Johnson, 1897)

Now we consider some image schemas in hafez sonnets.

\subsection{Path Schemas}

A path schema is an image schema that involves physical or metaphorical movement from place to place, and consists of a starting point, a goal, and a series of intermediate points (Johnson, 1980).

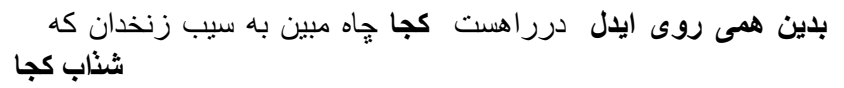

Take your focus from your chin to the trap on the path hence,

Where to $\mathrm{O}$ heart in such hurry you go whence?

Heart is a symbol of love and feeling. The lover has so deeply fallen in love that he cannot care the probable problems.

Two image schemas are used in this verse:

1) Lover is strongly in love with the sweetheart. In other words, sweetheart's love is considered as a container including lover existence as a content. First, lover must be engrossed in sweetheart's love (containment schema, it is explained in the following part) then, start moving towards her.

2) The beauty and strength of sweetheart's love have made his heart, which is an abstract concept, move away towards her and interestingly, it is in a hurry to go there. In the real world, just physical objects can be moved from one place to another but, in here the heart of the lover like all physical objects has found the capability to be moved and it is going towards sweetheart and this has formed path schema in here.

Starting point: heart of the lover, intermediate point: the distance between lover and sweetheart, destination: sweetheart

\subsection{Containment Schema}

A containment schema is an image schema that involves a physical or metaphorical boundary, enclosed area or volume, or excluded area or volume (Johnson, 1980).

$$
\text { فغان كاين لوليان شوخ شيرين كار شهر آشوب جنان بردند صبر از دل }
$$

$\mathrm{O}$ ! When these fair perfidious maids, Whose eyes our secret haunts in fest, Their dear destructive charms display, And robs my wounded soul of rest,
As tartars seize their destin'd prey.

In the second verse, the poet says, " these fair perfidious maids have taken rest from his wounded soul". In Farsi sonnet patience is used for rest and heart for wounded soul respectively.

In this verse, two schemas are used:

1) The wounded soul (heart) has found the properties of physical objects, (they all are concrete and take up some space) and is considered as a container and, rest (patience) as a content, that used to inhabit in it (wounded soul). So the containment schema is used in here. Hafez says that, before falling in love in the past, patience used to be in loverś heart but, the sweetheart and her beauty has made patience leave his heart and this has made him impatient.

2) The beauty and love of the sweetheart has moved rest (patience) away from the lover woundedś soul (heart). In fact rest like all physical phenomena, has found the capability to be moved and has left the soul of lover. Starting point: the heart of the lover, intermediate point: the distance between lover and sweetheart, destination: lover

Path schema is also used in this verse.

\subsection{Force Schema}

A force schema is an image schema that involves physical or metaphorical causal interaction. In includes the following elements:

A source and target of the force

A direction and intensity of the force

A path of motion of the source and / or target

A sequence of causation (Johnson, 1980).

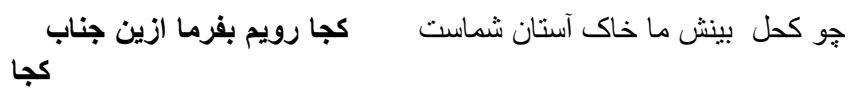

My eye liner is the dust of your door and fence

Where shall I go, tell me, you command me whence?

The lover eulogizes the sweetheart and says, "I have no other ways to go". Two image schemas is used in this verse:

1) Lover is strongly in love with the sweetheart. In other words, sweetheart's love is considered as a container containing lover existence as a content. So containment schema is formed in here.

2) Beauty and the strength of sweetheart's love has blocked all possible roads in front of him except the one (that is) led to her. In other words, the power of love is considered as a big obstacle and it has blocked all ways, and lover has so deeply fallen in love that he is not able to get it over. So, force schema is also used in here.

\subsection{Flavor Schema}

A Flavor schema is an image schema (that is) formed based on the human beings experiment of tasting different flavors. If we use this experience to describe abstract concepts metaphorically then, we are using flavor schema.

(Abedimoghdam, 2004). 


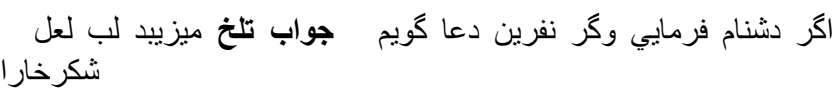

What cruel answer have I heard!

And yet, by heaven, I love thee, still:

Can aught be cruel from thy lip?

Yet say, how fell that bitter word

From lips which streams of sweetness fill,

Which nought but drops of honey sip?

We normally use four major flavors (sour, sweet, bitter, salty) to describe the flavors of edible things that all are concrete and can be tasted. If we use these flavors to describe the abstract concepts metaphorically then, we are using flavor schema. In the second verse, bitter is accompanied by $\square$ word $\square$,which is an abstract concept, in order to describe it metaphorically, and it has formed flavor schema in here.

\subsection{Measure Schema}

Measure schema is an image schema (that is) used to describe the length and width of abstract concepts metaphorically, (Behtooi, 2007).

$$
\text { شكر فروش كه عمرش دراز باد جرا }
$$

Thou merchant who dost sweetness nend

(Long May kind heav'n thy life defend!)

Ah, why unfriendly thus forget

Thy am'rous a weet - billed parroquet?

We usually use adjectives such as short,long, wide, narrow, to describe the properties of physical objects that all have the definite shape and take up some room. If we use these adjectives to describe abstract concepts metaphorically, then we are using measure schemas. Here life, that is an abstract concept, has found the specifications of physical objects and its length has been measured.

\subsection{Animals Schema}

In all cultures, special characteristics are ascribed to some animals based on their position in the cultures and they are known as the symbols of those characteristics. For example, in Iranian culture, eagle is a symbol of power and magnificent while fly is a symbol of weakness and silliness. If we use the names of those certain animals to ascribe their special characteristics to people then, we are applying animal schemas (Abedimoghdam, 2004).

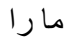

صبا به لطف بكو آن غزال رعنا را كه سر به كوهو بيابان توداده اي

Go, friendly zephyr! whisp'ring greet

Yon gentle fawn with slender feet;

Say that inquest of her I rove
The dangerous steeps, the wilds of love.

In Iranian culture, gazelle is a symbol of sweetheart and beauty. It has so beautiful eyes and slender feet. In this verse, the tall gazelle, which is so beautiful and attractive, living in the field is considered as the symbol of sweetheart. In Farsi literature, lovers usually leave their homes and cities when they are deeply in love with their sweethearts, and take refuge into the desert. Lover asks saba (breez) to kindly say to his sweetheart (gazelle) that, your love and beauty has led me into the desert.

\subsection{Manner Schema}

Manner schema is an image schema that describes the hardness, softness and thickness of abstract concepts metaphorically, (Behtooi ,2007).

$$
\begin{aligned}
& \text { راست نرنجيم ما ولى هبيج عاثق سخن سخت به از كل بخندد كه } \\
& \text { معشوق نحفت }
\end{aligned}
$$

The rose laughed: "You will find that we at truth show no distress"

But, never did a lover harsh words his love so press.

Hard, soft, thin and thick can just be used to describe the properties of physical objects that all are visible, taking up some space and having definite shape. In the second verse, word, which is an abstract concept, has found the properties of physical phenomena and is accompanied by harsh to be described metaphorically.

\subsection{Sensory Schema}

Sensory schema is an image schema in which sense verbs such as seeing, hearing, tasting, smelling, touching, can be accompanied by abstract concepts to describe them metaphorically. (Behtooi,2007)

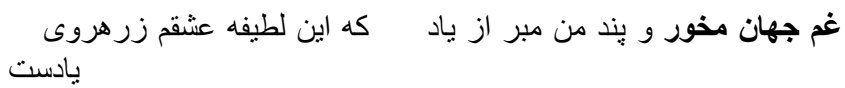

Suffer not grief for the world: take not my counsel from thy mind:

For, a way farer, I recollect his sweet saying:

In the real world, sense verbs are just used to describe physical phenomena, which are either physical or produced by people and animals like sounds. But, in this verse sorrow, which is an abstract concept, has found the properties of edible things that all are concrete and can be tasted, and it is accompanied by eating.

\subsection{Possessive Schema}

Possessive schema is an image schema that is formed based on peopleś possessive experience. The most sensible object that is possessed by people is the possession of the members of their bodies. We can also mention the 
possession of physical objects. If we make ourselves the possessors of abstract concepts, then we are using possessive schema. (Behtoi,2007)

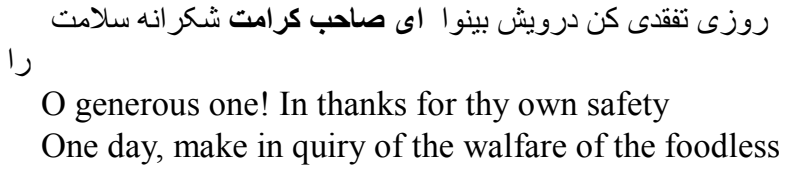

We normally possess physical objects that all take up some space and can be touched. Moreover, we have to pay for them and we may lose them sometime. But, in the first verse generosity, one of the owner ś characteristics, which is an abstract concept has found the specifications of physical objects and is possessed by its owner. Interestingly, he can have it as long as he stays alive in a free way.

\subsection{Members of the Body Schema}

The body of all beings has special and different structure. But, what is common among all of them is the members of their bodies. If we ascribe this characteristics (the members of the body) to abstract concepts and physical objects that lack the body and members of it, then we are using the members of the body schema.(Abedi moghadam, 2004)

$$
\text { تا سر زلف تو در دست نسيم افتاد ست دل سودازده از غصه دو نيم }
$$

Since thy tress-tip, into the power of the breeze, fell, My distraught heart, into two pieces on account of grief, fell

In the real world, it is just beings that have bodies and their bodies also have special members and structure (we do not consider some objects such as dolls, having the bodies in here). But, in the first verse, hair that itself is a part of the body (an unnecessary part of the head, people can live without it) is considered as a being, having a head as a main member of it just like the body of all beings.

\subsection{Color Schema}

Color schema is an image schema in which, abstract concepts like physical objects are considered as having colors.(Abedimoghadam,2004)

$$
\text { انجه زرمى شود از برنو ان قلب سياه يميايست كه در صحبت }
$$

By whose ray, the dull alloy becometh gold, that

Is an alchemy that is in the society of Darvishes.

Color is one of the most important specifications of physical objects because they all are visible and under the influence of Sun ś rays. But, if abstract concepts that are just in the mind are given this properties (color) then, we are using color schema, and describing them metaphorically. Heart, which is an abstract concept, is a symbol of feeling and love, but in the first verse, a color (black) is used to describe it metaphorically.

We use this schema metaphorically and widely not only in poems but in every day language as well, for example goodness is white, badness is black.

\subsection{Distance Schema}

According to the physics rules, the space between two tangible substances is called distance. If we consider distance for abstract concepts, then we are using distance schema.(Behtooi,2007)

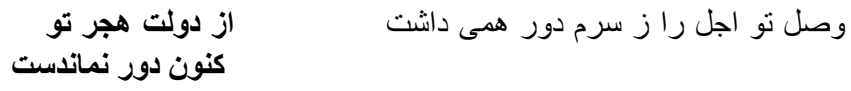

Union with Thee kept death from my head:

Now, from the fortune of separation from Thee, far, it hath remained not.

We normally say two or more physical objects are close or far from each other. Here, lover says to sweetheart, my goal (union of you and me) made death move away from me and I definitely know that your separation from me does not take long. Separation, which is an abstract concept, has found the properties of all physical objects (distance) and can be either near or far. In this verse, lover says that separation is not far and it is going to be finished and he is going to accomplish his goal (union of sweetheart and him).

\section{Conclusion}

Image schemas are conceptual structures derived from physical experiences, cultural background and ideology of a nation. All human beings based on their unique characteristics have access to a universal collection of image schemas, such as containment, path and force schemas. But, as being physically and facially different, cognitively people of nations based on their culture and ideology give priority to some of image schemas differently. This fact considered by Lakoff in forming conceptual metaphors and cultural differences in Metaphor we live By. That is why all image schemas mentioned by Johnson were not used in analyzing the corpus of this article. On the other hand, some image schemas mentioned by two Iranian researchers, were used suitably. Interestingly, despite the changes in social patterns, people living in the age of technology use the same image schemas as people in Hafez age. This can be proven by Hafez poem.

\section{References}

[1] Croft, W. and Cruse, D.A. (2004).Cognitive Linguistics. New York: Cambridge University Press.

[2] Johnson, M. (1987). The Body in the Mind: the bodily Basis of Meaning, Imagination, and Reason. Chicago: University of Chicago Press. 
[3] Kemmer, S. (2007). About cognitive linguistics. Microsoft Internet Explorer.

[4] Lakoff, G and Johnson, M. (1980). Metaphors we live By. Chicago: University of Chicago press .

[5] Langacker, R. (1990). Concept, Image and Symbol. The Cognitive Basis of Grammar. Berlin Mouton de Gruyter.

[6] Lakoff, G. (1987). Women, Fire and Dangerous Things. What Categories Reveal About the Mind Chicago: University of Chicago Press.

[7] Rohrer,T. (2006). 'Image Schemata in the Brain', in Beate, Hampe (ed.) From Perception to Meaning: Image schemas in Cognitive Linguistics, Berlin: Mouton de Gruyter.

[8] Lakoff, G and Turner, M. (1989). More than cool Reason. University of Chicago.
[9] Lakoff, G. (1988). Cognitive Semantics, in U.ECO etal (eds) Meaning and Mental Representations, Bloomington and Indianapolis: Indian University Press.

[10] Abedimoghdam, Hoda. (2004), Image schemas in studying metaphors in Farsi. Azad University press.

[11] Behtooi, Zohreh. (2007). Image schamas in studying metaphors in Hafez sonnets. Azad University press.

[12] Lawley,J.andTompkins,P.(2000).Metaphors in

[13] Mind:Transformation through Symbolic Modelling. The Developing Company Press.

[14] Arbery, A.J. (1946). English translation of Hafez sonnets.

[15] Ghani and Ghazvini (2007). Hafez divan.

[16] Clark, H.W.(1891). English translation of Hafez sonnets. 